\title{
Spectrographic Analysis of Tantalum Ores and Related Materials*
}

\author{
By Nakaaki Oda and Mitsuru Idohara**
}

\begin{abstract}
Recent developments in the tantalum refining industry have demanded a handy method of analyzing tantalum ores and related materials such as intermediates and residues, for the control and improvement of the refining processes. By use of a medium quartz spectrograph the authors studied a spectrographic analysis for these materials, in which the sample was fused with a fusion flux, powdered, and then sparked with a Feussner spark source. As a result, a method suitable for routine analysis could be established. The factors investigated in the experiments were the fusion flux, amount of the flux to be added, fusion time, analytical gap, shape of the electrode, particle size and quantity of the sample to be fused, particle size of the fused sample to be sparked, analytical line pairs, and errors due to the sample preparation and the analysis.

The outline of the method obtained was as follows: A mixture of $100 \mathrm{mg}$ of finely ground sample and $50 \mathrm{mg}$ of $\mathrm{GeO}_{2}$ as an internal standard is carefully fused with $1.5 \mathrm{~g}$ of $\mathrm{KHSO}_{4}$, and the resultant melt is cooled, pulverized to $180 \mathrm{mesh}$, charged into cup-electrode, and sparked with a graphite counter electrode sharpened to a truncated cone. The standard samples are prepared from synthetic oxides by applying the same fusion treatment as described above. In the various tantalum ores and related materials, $\mathrm{Ta}, \mathrm{Nb}, \mathrm{Fe}, \mathrm{Mn}, \mathrm{Sn}, \mathrm{Ca}, \mathrm{Si}, \mathrm{Ti}, \mathrm{Al}, \mathrm{Cr}$ and $\mathrm{Mg}$ are determined over the range of $0.05 \sim 100 \%$ with a variation coefficient of $3 \sim 5 \%$, and the chemical and spectrographic results are closely consistent with each other.
\end{abstract}

(Received April 18, 1963)

\section{Introduction}

With the development of tantalum and niobium refining industry, the analysis of tantalum ores and intermediates or residues in the tantalum refining process has become increasingly important for the control of the process, improvement of the refining techniques and investigation of the material balances. As for an analytical method of tantalum ores, wet chemical method by Schoeller et al.(1) have been used in many laboratories. However, only a few papers have dealt with spectrographic analyses ${ }^{(2)(3)}$, and none is available on the high precison method for analyzing simultaneously tantalum and other elements contained

* Published in Japanese in the J. Japan Institute of Metals, 26 (1962), 288 (Studies on the Application of Quantitative Spectrochemical Analysis to the $\mathrm{Ta}, \mathrm{Nb}$ Refining Industry . 2nd Report). Presented at the annual meeting of Japan Institute of Metal in Tokyo, April, 1961.

** Physical and Chemical Research Laboratory, Nippon Soda Co., Takaoka, Toyama Prefecture. Japan.

(1) W.R. Schoeller: The Analytical Chemistry of Tantalum and Niobium, Chaman \& Hall Ltd., London (1937).

(2) Handbuch der Analytischen Chemie, Band Vb., Springer Verlag. Berlin (1957).

(3) B. Boudergues: Chim. Anal., 42 (1960), 421. in tantalum ores. The authors made a study of the spectrographic method to analyze simultaneously tantalum, and minor elements or impurities such as niobium, iron, maganese, tin, calcium, silicon, titanium, aluminum, chromium and magnesium in tantalum ores and tantalum containing materials, by using a medium quartz spectrograph.

During the course of the study, the following three problems have been arisen : (1) Spectrum of tantalum ores or related materials are so complicated that it has generally been considered to be difficult to analyze them with a medium quartz spectrograph. (2) Sample compositions change at an extensive range, and the chemical forms of samples are variant, and so that the preparation of standard sample is difficult. (3) Major elements, of which are hardly analyzable by a spectrographic method, must be determined. The authors tried to solve these problems with the following technique. At first the sample was fused with a large amount of potassium hydrogen sulphate as a flux. This reduces the samples and the standard samples prepared from oxides to a common chemical form. The potassium sulphate formed by the fusion serves as a diluent 
and spectroscopic buffer agent, thereby supressing the intensity of the complex spectrum of tantalum or niobium. Such a pretreatment endows the sample with a condition suitable for determining the major element, together with the use of a spark excitation. In this paper, the proposed technique is called a fusion sample powder-spark technique. Having validated the applicability on an industrial scale, the method has been used for the process of tantalum refining in the author's company since 1960 .

\section{Apparatus and Materials}

The apparatus and materials used for this study are as follows: Spectrograph: C. Zeiss medium quartz spectrograph Qu-24, with a three-step filter. Excitation source : Feussner spark generator. Densitometry : C. Zeiss spectralline photometor. Plate: Fuji process, spectroscopic. Electrodes : commercial graphite electrodes ( $5 \mathrm{~mm}$ in diameter) for spectrochemical analysis. carbonate-boric acid (or borax) mixture for the fusion of silicates for chemical analysis, and borax and sodium carbonate for the decomposition of ordinary ores. Each flux was added separately at a specified ratio indicated in Table 1 to the two standard materials which had been previously mixed with a half part of germanium dioxide as an internal standard. The resulting mixtures were fused, and pulverized after cooling. Then, the powder was packed into a cup of electrode (outside dia $5 \mathrm{~mm}$, inside dia $3 \mathrm{~mm}$ and depth $3 \mathrm{~mm}$ ) and sparked with the counter electrode (truncated cone : $5 \mathrm{~mm}$ in base dia., $3 \mathrm{~mm}$ in tip dia.) under the condition shown in Table 5 (gap : $3 \mathrm{~mm}$ ). From the obtained specimen, the differences in Seidel blackness of analytical line pairs $(\Delta W)$ were measured and their differences between the two standard materials $\left(\Delta W_{\text {oxide }}-\Delta W_{\text {ore }}\right)$ were compared. These results are given in Table 1 . In Table 1 , potassium hydrogen sulphate and potassium pyrosuphate have a

Table 1 Comparison of fusion and buffer effects of various fusion fluxes

\begin{tabular}{|c|c|c|c|c|c|}
\hline \multirow{2}{*}{ Fusion flux } & \multirow{2}{*}{$\begin{array}{l}\text { Added amt. of flux } \\
\text { (sample : flux) }\end{array}$} & \multicolumn{4}{|c|}{ Difference of $\Delta W$ between ore and synthetic oxide } \\
\hline & & $\mathrm{Ta}$ & $\mathrm{Nb}$ & $\mathrm{Fe}$ & Mn \\
\hline $\begin{array}{l}\mathrm{K}_{2} \mathrm{~S}_{2} \mathrm{O}_{7} \\
\mathrm{KHSO}_{4} \\
\mathrm{Li}_{2} \mathrm{CO}_{3}+\mathrm{H}_{3} \mathrm{BO}_{3} \\
\mathrm{Na}_{2} \mathrm{~B}_{4} \mathrm{O}_{7} \cdot 10 \mathrm{H}_{2} \mathrm{O} \\
\mathrm{Na}_{2} \mathrm{CO}_{3}+\end{array}$ & $\begin{array}{r}1: 6 \\
1: 7 \\
1: 7 \\
1: 10 \\
1: 8\end{array}$ & $\begin{array}{l}0.096^{*} \\
0.069^{*} \\
0.138^{*} \\
0.239^{*} \\
-\end{array}$ & $\begin{array}{l}0.035 \\
0.011 \\
0.077 \\
0.237^{*} \\
-\end{array}$ & $\begin{array}{l}0.060 \\
0.057 \\
0.163 \\
0.140 \\
-\end{array}$ & $\begin{array}{l}0.027 \\
0 \\
0.004 \\
0.132^{*} \\
0.419\end{array}$ \\
\hline $\begin{array}{l}\text { Digestion + }+ \text {-Ignition-Addition of } \mathrm{C} \\
\text { Addition of } \mathrm{C}\end{array}$ & $\begin{array}{l}1: 5 \\
1: 5\end{array}$ & $\begin{array}{l}0.022 \\
0.960^{* * *}\end{array}$ & $\begin{array}{l}0.163^{*} \\
0.150^{*}\end{array}$ & $\begin{array}{l}0.016 \\
0.583^{* * *}\end{array}$ & $\begin{array}{l}0.009 \\
0.215^{* * *}\end{array}$ \\
\hline
\end{tabular}

$\dagger$ Incomplete fusion, $\mathrm{H} \mathrm{HF}+\mathrm{H}_{2} \mathrm{SO}_{4}$,

* Significance, ** Highly significance

\section{Experimental}

In order to obtain the optimum conditions for the fused sample powder-spark technique, many factors such as sample preparation, excitation, analytical line pairs were investigated from the viewpoint of the precision and accuracy of the analytical values. With regard to the accuracy of the analytical values, the difference in blackness $(\Delta W)$ obtained by the analytical line pairs for the ore and synthetic oxide (as standard materials), having the same composition $\left(\mathrm{Ta}_{2} \mathrm{O}_{5} 64 \%, \mathrm{Nb}_{2} \mathrm{O}_{5} 14 \%, \mathrm{Fe}_{2} \mathrm{O}_{3} 3.8 \%, \mathrm{MnO}_{2} 11.6 \%\right.$, others $6.6 \%$ ), will be identical under the optimum analyticl condition. Consequently, the experiment was carried out to find such a level of the factor that gives the minimum values of difference in $\Delta W$ values between the two standard materials as described above. For convenience's sake, tantalum, niobium, iron and manganese, which are four important elements in tantalum ores and related materials, were mainly investigated and discussed.

Flux The suitable flux for this technique must have two effects; one is the effect of reducing constituents of various samples to a common form by fusion, and the other is the spectrochemical buffer effect. For this reason, the following compounds were experimentally investigated as possible fluxes; potassium pyrosulphate and potassium hydrogen sulphate for the fusion of tantalum ores ${ }^{(1)}$ for chemical analysis, alkali good flux effect. In view of higher fusional capacity than potassium pyrosulphate, potassium hydrogen sulphate was selected as the most suitable flux.

Electrode form, electrode gap and carbon powder addition For better precision, investigation was made on the main factors concerned, i.e., electrode form (truncated counter electrode, 4 and $1 \mathrm{~mm}$ in tip dia.), electrode gap $(2,3,4 \mathrm{~mm})$ and carbon powder additions (sample : carbon powder $=1: 0,1: 1 / 2,1$ : 1). Experiments were carried out with synthetic oxide consisting of $\mathrm{Ta}_{2} \mathrm{O}_{5} 30 \%, \mathrm{Nb}_{2} \mathrm{O}_{5} 30 \%, \mathrm{FeO} 5 \%, \mathrm{MnO}$ $4 \%$ and others $31 \%$. The results obtained are shown in Fig. 1. In Fig. 1, each dot is the mean value or standard deviation of the eight analytical results. From Fig. 1 it is known that the optimum conditions are $1 \mathrm{~mm}$ in tip diameter of the counter electrode and $4 \mathrm{~mm}$ in electrode gap, and that the addition of carbon powder is not necessary and the analytical gap should be rigidly controlled.

Amount of potassium hydrogen sulphate added Amount of potassium hydrogen sulphate added as the flux in the spectrographic analysis was required, from the viewpoint of sensitivity, to be reduced to such an extent as to effectuate the fusion and the buffer effect. The ratios of potassium hydrogen sulphate to a mixture of the sample ore and germanium dioxide $(2: 1)$ were investigated on the four levels of $1: 5.3,1: 8.0,1: 10$ and $1: 13.3$. The results indicated that a significant difference in $\Delta W$ values of the analytical line pairs 
between the two standard materials was observed only in tantalum line pairs at the ratio of $1: 5.3$. From the viewpoint of the fusional capacity and the buffer effect, the ratio of $1: 10$ would be most adequate. chemical forms of the two standard materials become almost identical. Consequently, the heating process can be terminated at any step between 3 and 5 .

Particle size and amout of sample An experi-
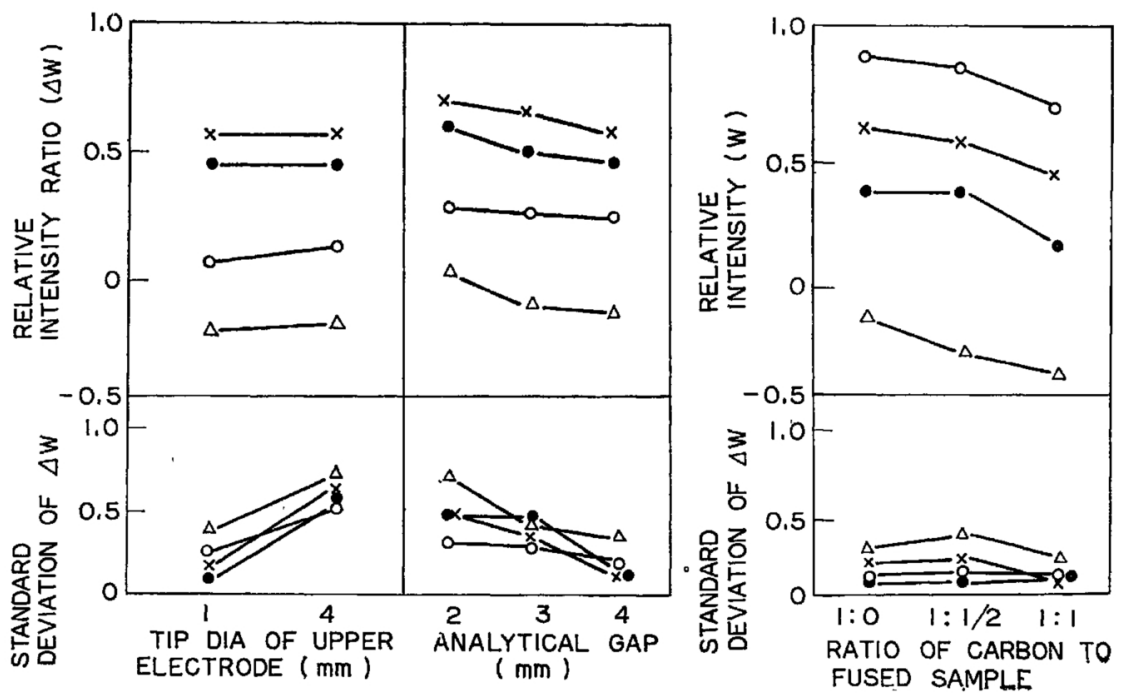

Fig. 1 Effects of analytical conditions on $\Delta W$ and $\sigma_{\Delta}: \mathrm{I}^{\circ}$

○: Ta $2684 \AA / G e 2651 \AA, \quad \triangle:$ Fe $2585 \AA / G e 2651 \AA$

- : Nb $2950 \AA /$ Ge $2651 \AA$, x : Mn $2949 \AA$ $/ G e 2651 \AA$

Fusion process In order to examine the fusing condition at each fusion step and the optimum fusion time, the differences in $\Delta W$ values between the two standard materials were measured at the following steps: (1) a sample was mixed with germanium dioxide and potassium hydrogen sulphate $(1: 1 / 2: 15)$, (2) the resultant mixture (1) was melted by heating with an alcohol lamp, (3) the liquird (2) was heated on a soft flame of an air-propane burner unitil the residues disappeared completely, (4i) the liquid (3) was heated on a full flame of the burner; usually the fusion might be accomplished at this step, (5) the liquid (4) was continuously heated intensely until a thin layer appeared on the surface of the liquid, (6) the liquid (5) was continuously heated until it dried up to a solid state. The results obtained are shown in Fig. 2 . In

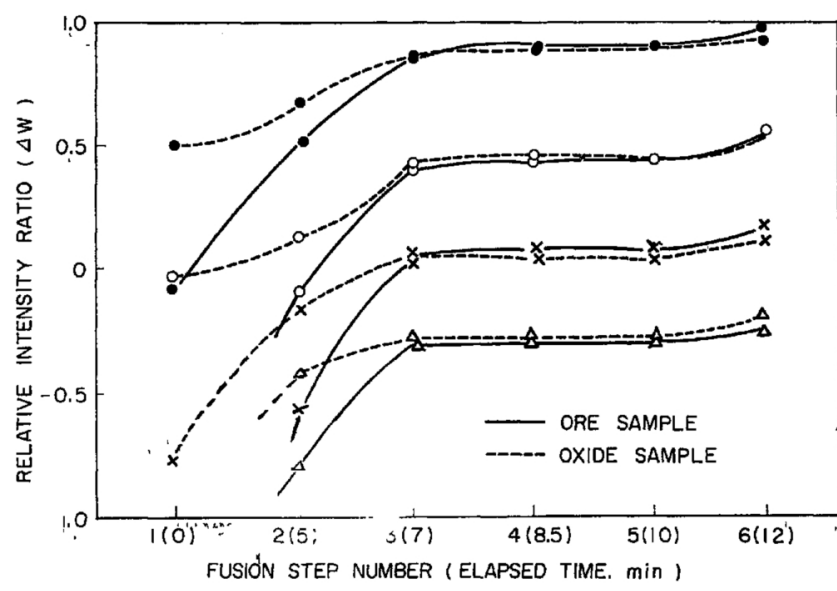

-Fig. 2 Relative intensity ratio at each fusion step

Fig, 2, the differences in $\Delta W$ values between the two standard materials disappear in the steps of 3 to 5 and $\triangle W$ values are held constant. This means that in step 3 the fusion is thoroughly accomplished and the ment was carried out to find out an optimum condition for the particle size and the amount of a sample to be fused in a $30 \mathrm{ml}$ porcelain crucible. For this purpose, the particle sizes $(-200$ mesh $20 \%,-200$ mesh 70 $\%)$ and amounts $(50,100,150 \mathrm{mg})$ of the sample were examined. As a result, it is known that the greater the particle size and the smaller the sample amount, the more the fusion become incomplete and $\Delta W$ decreases. Therefore, the suitable amount is decided to be $100 \sim 150 \mathrm{mg}$ and the particle size is required to be as fine as possible (about $70 \%$ up through 200 mesh).

Particle size of fused sample powder In a spark excitation of a powdered sample, it is known that a particle size of sample affects greatly the spectral intensity. Therefore, the relation between the particle size of the fused sample powder and the differences in blackness $(\Delta W)$ of the line pair was investigated. A synthetic oxide, whose composition is shown in Table 6 , was fused and pulverized in an agate mortar, and the pulverized powder was divided into three parts; the first part was kept in the as-powdered state with a $30 \%$ passability through 200 mesh (sample A), the second part was ground to $60 \%$ through 200 mesh (sample B) and the third part was further ground to 85 $\%$ through 200 mesh (sample C). When the $\Delta W$ values of the spectra of the three samples, were compard, it was found that the line intensity $(W)$ decreased and $\Delta W$ value varied significantly with the increase of the particle size. Accordingly, the particle size should be regulated on a certain level for both the analytical and the standard samples. For regulating the constant particle size, the sifting process was examined. The sample B was subdivided into two, one of which was sifted through 180 mesh (sample D). The samples $B$ and $D$ were successively analyzed fourteen times, and the mean values and the coefficients of variation 
were compard. The results are shown in Table 2 . The sample D, passed through 180 mesh, has better precision than the sample $B$, not sifted, although the accuracy is satisfactory in both cases.

Table 2 Influence of sifting on analytical precison

\begin{tabular}{l|c|c|c|c}
\hline & $\mathrm{Ta}_{2} \mathrm{O}_{5}$ & $\mathrm{Nb}_{2} \mathrm{O}_{5}$ & $\mathrm{FeO}$ & $\mathrm{MnO}$ \\
\hline Added \% & 50.0 & 10.0 & 9.0 & 4.1 \\
Found $\{\mathrm{B}$ (no-sifting) & 50.4 & 10.0 & 9.1 & 4.2 \\
av. \% $\mathrm{D}$ (sifting) & 50.1 & 10.2 & $\mathbf{9 . 1}$ & 4.4 \\
Unbiased $\left\{\boldsymbol{V}_{B}\right.$ & 11.1 & 0.28 & 0.80 & 0.056 \\
variation $\left(V_{D}\right.$ & 4.7 & 0.19 & 0.26 & 0.057 \\
$F_{O}\left(V_{B} / V_{D}\right)$ & 2.36 & 1.50 & 3.30 & 0.98 \\
Significance (Level) & $*(0.10)$ & $-(0.10)$ & $*(0.025)$ & $-(0.10)$ \\
\hline
\end{tabular}

Analytical line pairs The available line pairs of good precision with no interference line were selected. The synthetic oxide $\left(\mathrm{Ta}_{2} \mathrm{O}_{5} 50 \%, \mathrm{Fe}_{2} \mathrm{O}_{3}, \mathrm{Nb}_{2} \mathrm{O}_{5} 10 \%\right.$, $\mathrm{MnO}_{2}, \mathrm{SiO}_{2} 5 \%, \mathrm{SnO}_{2}, \mathrm{CaO}, \mathrm{Al}_{2} \mathrm{O}_{3}, \mathrm{TiO}_{2} 4 \%, \mathrm{Cr}_{2} \mathrm{O}_{3}$, $\mathrm{MgO} 2 \%$ ) was succesively analyzed seven times to calculate the analytical precision (coefficient of variation, $\sigma \%$ ) for each line pair. The investigated analytical line pairs and the obtained precisions are shown in Table 3 . The spectral lines marked with asterisks in Table 3 are selected as adequate lines with no interference line. be given to each operation in the sample preparation (referable to $\sigma_{S}$ ). In particular, the analytical operation should be repeated two or more times to minimize the error $\left(\sigma_{A}\right)$ due to the analysis for the substantial improvement of the precison $\left(\sigma_{T}\right)$.

\section{Analytical Method}

The analytical method established from the above experimental results is as follows :

Preparation of samples Weigh out $100 \mathrm{mg}$ of the finely ground sample into a $30 \mathrm{ml}$ porcelain crucible*1, and add $50 \mathrm{mg}$ of germanium dioxide as an internal standard and $1.5 \mathrm{~g}$ of potassium hydrogen sulphate as a flux. Heat the mixture carefully to avoid spattering with an alcohol lamp for about $5 \mathrm{~min}$, until the fused mass ceases to evolve and become yellowish. Then heat the mixture with a soft flame of the burner*2 for about $2 \mathrm{~min}$, until the unfused particle of the sample disappears and become red uniformly, and heat ${ }^{* 3}$ on a full flame of the burner for about $1.5 \mathrm{~min}$. Raise the crucible with tongs, and rotate it quickly and slantingly so that the melt can be attached to the inside wall of the crucible. Cool the crucible, take the melt out of the crucible and grind the melt to as fine as about 180 mesh $^{* 4}$ in the agate mortar.

Table 3 Precision $(\sigma \%)$ for various analytical line pairs

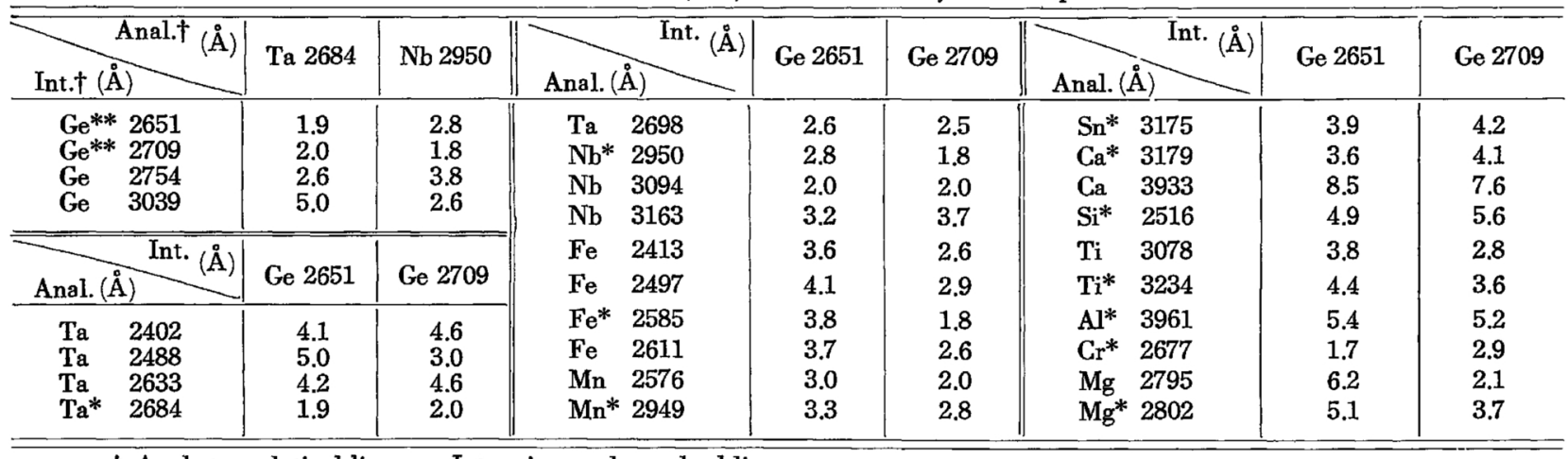

$\dagger$ Anal. : analytical line. Int. : internal standard line.

* Selected analytical line.

** Selected internal standard lines, either of which may be used with the analytical line.

Errors due to sample preparation and analysis The total analytical error $\left(\sigma_{T}\right)$ can be divided into two, one due to the sample preparation, $\left(\sigma_{S}\right)$ (samplingfusion-pulverization) and the other due to the analysis $\left(\sigma_{A}\right)$ (excitation-development-densitometry). For higher analytical precision, both of the errors were estimated statistically with a nested system. The result is shown in Table 4. The error resulting from the sample preparation is almost equal to that from the analysis.

Table 4 Errors due to the operations of sample preparation and analysis

\begin{tabular}{|c|c|c|c|c|}
\hline & $\mathrm{Ta}_{2} \mathrm{O}_{5}$ & $\mathrm{Nb}_{2} \mathrm{O}_{5}$ & $\mathrm{FeO}$ & $\mathrm{MnO}$ \\
\hline Added $\%$ & 50.0 & 10.0 & 9.0 & 4.1 \\
\hline Found av. \% & 50.1 & 10.2 & 9.1 & 4.4 \\
\hline $\begin{array}{l}\text { Standard } \\
\text { dev. }(\sigma)\end{array}\left\{\begin{array}{l}\text { Sample prepn. } \\
\text { Analysis }\end{array}\right.$ & $\begin{array}{l}2.14 \\
0.93\end{array}$ & $\begin{array}{l}0.35 \\
0.29\end{array}$ & $\begin{array}{l}0.34 \\
0.41\end{array}$ & $\begin{array}{l}0.18 \\
0.17\end{array}$ \\
\hline $\begin{array}{l}\text { Variation } \\
\text { coeff. }(\sigma \%)\end{array}\left\{\begin{array}{l}\text { Sample prepn. } \\
\text { Analysis' }\end{array}\right.$ & $\begin{array}{l}4.2 \\
1.8\end{array}$ & $\begin{array}{l}3.4 \\
2.9\end{array}$ & $\begin{array}{l}3.7 \\
4.4\end{array}$ & $\begin{array}{l}4.1 \\
3.8\end{array}$ \\
\hline
\end{tabular}

With regard to $\mathrm{Ta}$, the former is somewhat greater than the latter. Therefore, the utmost caution should
Preparation of the standard samples A set of the standard samples is prepared by applying the same fusion-pulverization treatment to synthetic oxides.

Analytical condition The analytical conditions are shown in Table 5 . In usual practice, it is recommended to repeat the determination of the same sample two or more times.

\section{Applicability of the Method}

Analytical range The analytical concentration range of each element is shown in Table 6. The working curves are biased from linearity more than

*1 It is recommended not to use an old crucible which has an unsmooth inside surface, because the melt can be hardly taken off.

*2 A propane-air burner may be used instead.

*3 Heat until a thin film forms on the surface of the melt, but if the film does not dissolve into the melt even by stirring the crucible, overheating is done.

*4 Usually it is not necessary to grind a sample to 180 mesh completely, but only the powder through 180 mesh after pulverization can be used as the analytical sample. 
about $10 \%$ for $\mathrm{FeO}, \mathrm{MnO}, \mathrm{TiO}_{2}, \mathrm{Al}_{2} \mathrm{O}_{3}$ and more than about $30 \%$ for $\mathrm{Nb}_{2} \mathrm{O}_{5}$, and are linear for other elements in the concentration range for the practical analysis. The determinable concentrations listed in Table 6

Table 5 Analytical conditions

\begin{tabular}{l|l}
\hline \hline Spectrograph & C. Zeiss medium quartz spectrograph $Q \mathrm{u}-24$ \\
Excitation source & Feussner spark source $(\mathrm{V}=12 \mathrm{KV}$, \\
& $\mathrm{C}=0.0033 \mu \mathrm{F}, \mathrm{L}=0.08 \mathrm{mH})$ \\
Exposure time & $60 \mathrm{sec}$ \\
Analytical gap & $4 \mathrm{~mm}$ \\
Slit & $1.5 / 100 \mathrm{~mm}$ \\
Electrodes & $\begin{array}{l}\text { Graphite rods }(5 \mathrm{~mm} \phi) \text { for spectroscosy : } \\
\text { upper ; conical end dia 1 mm } \phi\end{array}$ \\
Plate & Fuwer ; cup dia $3 \mathrm{~mm} \phi$, depth $5 \mathrm{~mm}$ \\
Analytical lines & See Table 3 \\
\hline \hline
\end{tabular}

sion could be improved by repeating the determination. Such a repetition is not so time-comsuming that the proposed method may be suitable for the routine practice.

Accuracy The accuracy is satisfactory for the following reasons. The analytical results are scarcely affected by the variation of concentration over $1 \sim$ $100 \%$ for $\mathrm{Ta}_{2} \mathrm{O}_{5}$, about $1 \sim 50 \%$ for $\mathrm{Nb}_{2} \mathrm{O}_{5}, \mathrm{FeO}$, about $0.05 \sim 10 \%$ for $\mathrm{Cr}_{2} \mathrm{O}_{3}, \mathrm{MgO}$, and about $0.1 \sim$ $30 \%$ for other impurities, and also the means of the analytical values are in good agreement with the theoretical values as shown in Table 6. In addition, it is known from Table 7 that in practice the analytical results are little affected by the variation in composition and chemical forms of the sample, and that the results are closely consistent with the wet chemical results of other laboratories.

Table 6 The precision and concentration range investigated

\begin{tabular}{|c|c|c|c|c|c|c|c|c|c|c|c|}
\hline \multirow{2}{*}{ Fused sample No. } & \multicolumn{11}{|c|}{ Found values $\uparrow(\%)$} \\
\hline & $\mathrm{Ta}_{2} \mathrm{O}_{5}$ & $\mathrm{Nb}_{2} \mathrm{O}_{5}$ & $\mathrm{FeO}$ & $\mathrm{MnO}$ & TiO & $\mathrm{CaO}$ & $\mathrm{SnO}_{2}$ & $\mathrm{SiO}_{2}$ & $\mathrm{Al}_{2} \mathrm{O}_{3}$ & $\mathrm{Cr}_{2} \mathrm{O}_{3}$ & $\mathrm{MgO}$ \\
\hline $\begin{array}{l}1 \\
2 \\
3 \\
4 \\
5 \\
6\end{array}$ & $\begin{array}{l}50 \\
47 \\
52 \\
48 \\
51 \\
51\end{array}$ & $\begin{array}{r}9.9 \\
9.8 \\
10.5 \\
9.8 \\
10.3 \\
10.6\end{array}$ & $\begin{array}{l}8.7 \\
8.6 \\
9.5 \\
8.7 \\
9.1 \\
9.4\end{array}$ & $\begin{array}{l}4.5 \\
4.2 \\
4.6 \\
4.1 \\
4.5 \\
4.4\end{array}$ & $\begin{array}{l}4.0 \\
4.0 \\
4.3 \\
3.9 \\
4.2 \\
4.4\end{array}$ & $\begin{array}{l}4.0 \\
4.0 \\
4.0 \\
3.7 \\
4.0 \\
4.1\end{array}$ & $\begin{array}{l}4.1 \\
3.9 \\
4.3 \\
3.8 \\
4.0 \\
4.3\end{array}$ & $\begin{array}{l}4.9 \\
\mathbf{5 . 0} \\
\mathbf{5 . 5} \\
\mathbf{5 . 0} \\
\mathbf{5 . 0} \\
\mathbf{5 . 3}\end{array}$ & $\begin{array}{l}3.7 \\
3.7 \\
4.1 \\
4.1 \\
4.2 \\
4.2\end{array}$ & $\begin{array}{l}2.1 \\
2.0 \\
2.3 \\
2.0 \\
2.2 \\
2.2\end{array}$ & $\begin{array}{l}2.0 \\
2.0 \\
2.1 \\
1.9 \\
2.0 \\
2.1\end{array}$ \\
\hline $\begin{array}{l}\text { Average } \\
\text { Added }\end{array}$ & $\begin{array}{l}49.8 \\
50.0\end{array}$ & $\begin{array}{l}10.1_{5} \\
10.00\end{array}$ & $\begin{array}{l}9.0_{0} \\
9.00\end{array}$ & $\begin{array}{l}4.3_{8} \\
4.10\end{array}$ & $\begin{array}{l}4.13 \\
4.00\end{array}$ & $\begin{array}{l}3.9_{7} \\
4.00\end{array}$ & $\begin{array}{l}4.07 \\
4.00\end{array}$ & $\begin{array}{l}5.1_{2} \\
5.00\end{array}$ & $\begin{array}{l}4.0_{0} \\
4.00\end{array}$ & $\begin{array}{l}2.1_{3} \\
2.00\end{array}$ & $\begin{array}{l}2.0_{1} \\
2.00\end{array}$ \\
\hline $\begin{array}{l}\text { Precision }(\sigma \%) \\
\text { Conc. range investigated }\end{array}$ & $\begin{array}{c}3.9 \\
100 \sim 1\end{array}$ & $\begin{array}{c}3.1 \\
50 \sim 0.5\end{array}$ & $\begin{array}{c}3.9 \\
50 \sim 0.1\end{array}$ & $\begin{array}{c}4.5 \\
30 \sim 0.1\end{array}$ & $\begin{array}{c}4.8 \\
30 \sim 0.5\end{array}$ & $\begin{array}{c}4.0 \\
30 \sim 0.5\end{array}$ & $\begin{array}{c}4.8 \\
30 \sim 0.5\end{array}$ & $\begin{array}{c}4.6 \\
30 \sim 3\end{array}$ & $\begin{array}{c}4.9 \\
30 \sim 0.1\end{array}$ & $\begin{array}{c}5.5 \\
10 \sim 0.1\end{array}$ & $\stackrel{2.9}{10 \sim 0.05}$ \\
\hline
\end{tabular}

$\dagger$ Mean values obtained from two sparkings of the same fused sample.

could be extended by some technical modification.

Analytical precision The coefficient of variation (analytical precision) was calculated as follows: Six aliquote samples, taken out of the synthetic oxides were treated separately with the fusion-pulverization
The results of a practical application Some results of the practical application of this method to the analysis of tantalum ores and tantalum intermediates are shown in Table 7. From such an extensive applicability, it is evident that the present method

Table 7 Examples of analytical results

\begin{tabular}{|c|c|c|c|c|c|c|c|c|c|c|c|c|}
\hline Sample & $\mathrm{Ta}_{2} \mathrm{O}_{5}$ & $\mathrm{Nb}_{2} \mathrm{O}_{5}$ & $\mathrm{FeO}$ & $\mathrm{MnO}$ & $\mathrm{SnO}_{2}$ & $\mathrm{CaO}$ & $\mathrm{SiO}_{2}$ & $\mathrm{TiO}_{2}$ & $\mathrm{Al}_{2} \mathrm{O}_{3}$ & $\mathrm{Cr}_{2} \mathrm{O}_{3}$ & MgO & Total \\
\hline Tantalite A & $\begin{array}{c}75 \\
(76)\end{array}$ & $\begin{array}{c}4.9 \\
(6.4)\end{array}$ & $\begin{array}{c}12 \\
(12)\end{array}$ & $\begin{array}{c}2.7 \\
(1.8)\end{array}$ & $\begin{array}{l}1.08 \\
(1.3)\end{array}$ & $\begin{array}{r}1.17 \\
(0.8)\end{array}$ & $<3$ & $\begin{array}{c}1.1 \\
(0.5)\end{array}$ & 0.2 & 0.27 & 0.05 & 98.47 \\
\hline Tantalite B & $\begin{array}{c}66 \\
(64.19)\end{array}$ & $\begin{array}{c}10.4 \\
(10.49)\end{array}$ & 0.65 & 10.5 & $\begin{array}{c}7.6 \\
(6.8)\end{array}$ & 0.44 & " & $\begin{array}{c}2.14 \\
(1.68)\end{array}$ & 0.5 & 0.15 & 0.05 & 98.43 \\
\hline Microlite & $\begin{array}{c}70 \\
(69.95)\end{array}$ & $\begin{array}{l}5.1 \\
(3.70)\end{array}$ & 0.80 & 0.66 & 1.95 & 19 & $"$ & $\begin{array}{c}0.42 \\
(0.21)\end{array}$ & 0.7 & 0.29 & 0.05 & 98.97 \\
\hline Low grade ore & 16 & 16.5 & 23 & 4.5 & 0.75 & 0.30 & 10 & 28 & 0.2 & 0.10 & 0.20 & 99.55 \\
\hline Intermediate & 52 & 33 & 4.6 & 0.23 & $<0.5$ & 0.10 & $<3$ & $<0.1$ & 6.9 & 2.3 & 0.08 & 99.21 \\
\hline Concentrate & 86 & 9.5 & 0.35 & 0.10 & $"$ & 0.14 & $"$ & $"$ & 0.48 & $<0.1$ & 0.04 & 96.61 \\
\hline Residue & 13 & 3.7 & 30 & 17 & ” & 0.19 & " & " & $>30$ & 1.0 & 0.22 & $>94.65$ \\
\hline
\end{tabular}

The values in brackets are chemical results of other laboratories.

procedure. Each powder sample was analyzed two times, the two analytical values of which were averaged. From the six mean values the coefficient of variation was calculated as shown in Table 6. The coefficient of variation by this method is estimated to be about 3 to 5 percent. This would not be very satisfactory for the determination of tantalum as the major constituent element in ores, but in practice, the preci- is a reliable source for the practical analysis of tantalum ores and related materials.

\section{Summary}

Spectrographic analysis for tantalum ores and related materials was studied by a fusion sample powder-spark technique. The present method, consisting of the fusion of a sample with potassium 
hydrogen sulphate, the pulverization and the spark excitation was established as a result of investigations of the excitation condition, flux, particle size, fusing condition, analytical line pairs, etc. Eleven elements, including tantalum and niobium, in tantalum ores and related materials such as intermediates or residues in tantalum refining products, can be determined simultaneously with the precision of $3 \sim 5 \%$ (two-time determination) by this method. The results obtained are hardly affected by the chemical composition and form of the sample and are in good agreement with those by wet chemical analysis.

\section{Acknowledgement}

The authors wish to express their gratitude to President Teiji Ohwada, Managing Director Tohma Tanaka, Katsumi Oga. Ex-manager late Kenichi Fukushima of Takaoka plant, and other staff members of the Nippon Soda Co. Ltd., for their encouragement and guidance. Thanks are also due to Dr. Sadayuki Tsunoo for his stimulating discussion and to Messrs. Noboru Orita and Yoshiaki Takashima for their kind cooperations. 